\title{
An Experiment on Power Properties in a Small-Scaled Wind Turbine Generator
}

\author{
Jee-Ho Kim, Hyun-Dai Yang, Kyu-Jin Lee, Sung-Do Song, Sung-Hoon Park, Joong-Ho Shin
}

Department of Mechanical Design \& Manufacturing, Changwon National University, Changwon 641-773, Korea. Email: jiho2362@naver.com, neadai20@nate.com

Received September 2013

\begin{abstract}
This study configures a simple wind tunnel using a blower for generating wind energy, which is equivalent to natural wind, and a test system that measures properties of power. Also, the mechanical and electrical power in a small-scaled wind turbine are empirically measured to analyze the relationship between the mechanical and electrical power.
\end{abstract}

Keywords: Small-Scaled Wind Turbine; Vertical Axis Windmill; Gearbox; Mechanical Power; Electrical Power

\section{Introduction}

Environmental issues including ozone depletion have become to the front because of exhausting natural resources and carbon dioxide emissions according to sustainable use of fossil fuels during industrialization processes. Although there are some efforts that are starting to control such carbon dioxide emissions based on UNFCCC, it is not possible to fundamentally solve the energy dependency of fossil fuels. Thus, studies on new and renewable energy have been largely conducted throughout the world.

Wind power that is one of the new and renewable energy has been considered as a subject in many researches because it represents clean energy and low power generation costs. Although the wind power has been developed based on large-scaled power generation systems around the world, researches on small-scaled wind power generation systems have been largely performed in recent years. However, such small-scaled power generation systems show difficulties in starting a system and generating power under the conditions of varying wind directions and velocities at a low altitude because it applies a miniature version of the large-scaled system.

In this study a simple wind tunnel is installed to develop a small-scaled wind turbine generator as a vertical axis drag type that shows efficient power generation under the conditions of varying wind directions and velocities through introducing a simple wind tunnel. Then, the mechanical and electrical power generated by a windmill in a given wind speed are empirically measured to analyze the relationship between the mechanical and electrical power.

\section{Definition of Power}

First, Wind flow can generate mechanical energy by rotating a windmill with blades and the mechanical energy can produce electrical energy through a generator. The wind power generated by wind is presented as Equation (1) where Pw is power (W), p is air density $\left(\mathrm{kg} / \mathrm{m}^{3}\right), A$ is a projected area $\left(\mathrm{m}^{3}\right)$, and $\mathrm{V}$ is wind speed $(\mathrm{m} / \mathrm{s})$.

$$
\mathbf{P w}=\mathbf{p} \mathbf{A V}^{3} / \mathbf{2}
$$

The mechanical power is defined by a mechanical parameter, Torque (T), and angular speed (w) as Equation (2). Figure 1(a) shows an experimental configuration for measuring its mechanical property.

$$
\mathbf{P m}=\mathbf{T} \cdot \mathbf{w}
$$

The electrical power is defined by electrical parameters, Voltage (V) and Current (I), as Equation (3). Figure 1(b) shows an experimental configuration for measuring its electrical property [5].

$$
\mathbf{P e}=\mathbf{V} \cdot \mathbf{I}
$$

\section{Wind Tunnel Conditions}

The output of the blower in the configured wind tunnel presented in Figures $\mathbf{2}$ and $\mathbf{3}$ can be controlled with six different steps and the wind speed can also be varied by changing the steps. Table 1 shows the average wind speed in which the measurement is performed with a distance of $3.5 \mathrm{~m}$ from the blower to the wind turbine generator.

\section{Small-Scaled Wind Generator}

The small-scaled wind turbine generator as a vertical axis 


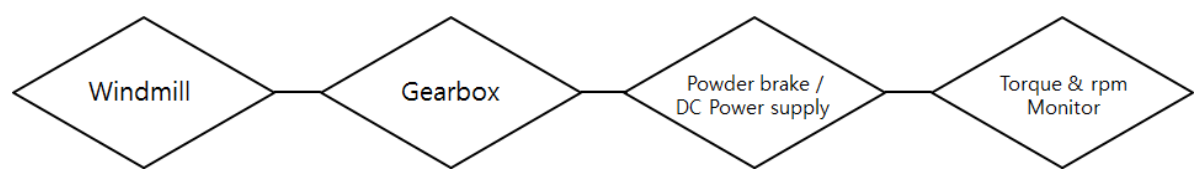

(a) Mechanical power

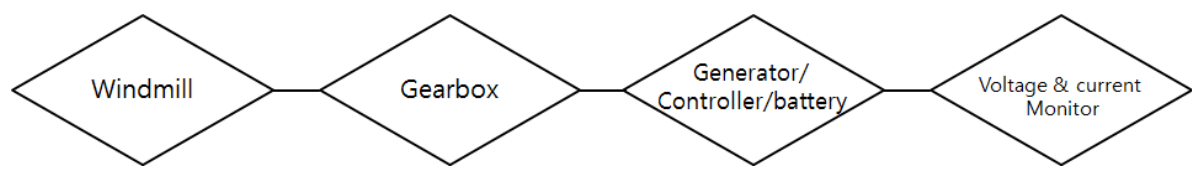

(b) Electrical power

Figure 1. Block diagram for power evaluation process.

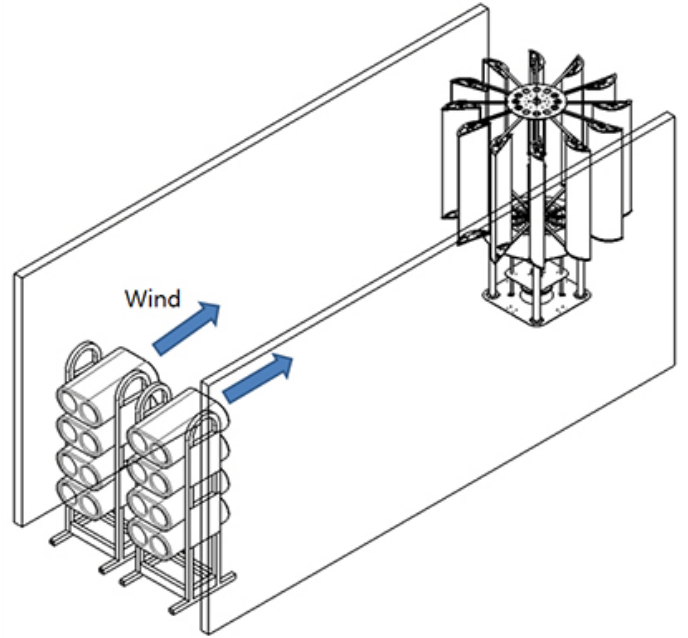

Figure 2. Wind tunnel.

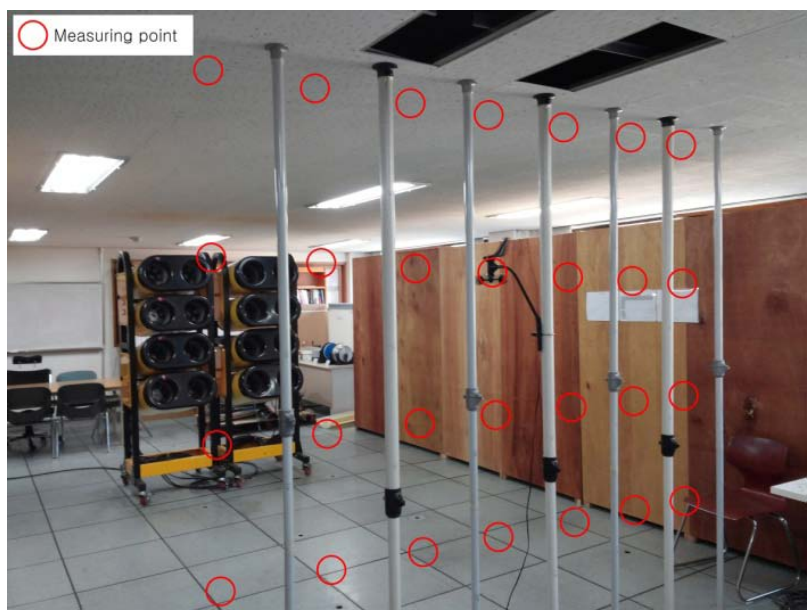

Figure 3. Anemometry.

Table 1. Average wind speed at blower step.

\begin{tabular}{ccccccc}
\hline & 1 setp & 2 setp & 3 setp & 4 setp & 5 setp & 6 setp \\
\hline deepS dniW (s/m) & 3.68 & 4.49 & 5.75 & 6.8 & 7.6 & 7.96 \\
\hline
\end{tabular}

drag type consists of four different sections such as windmill, gearbox, generator, and controller. The overall configuration is presented in Figure 4. As the windmill is

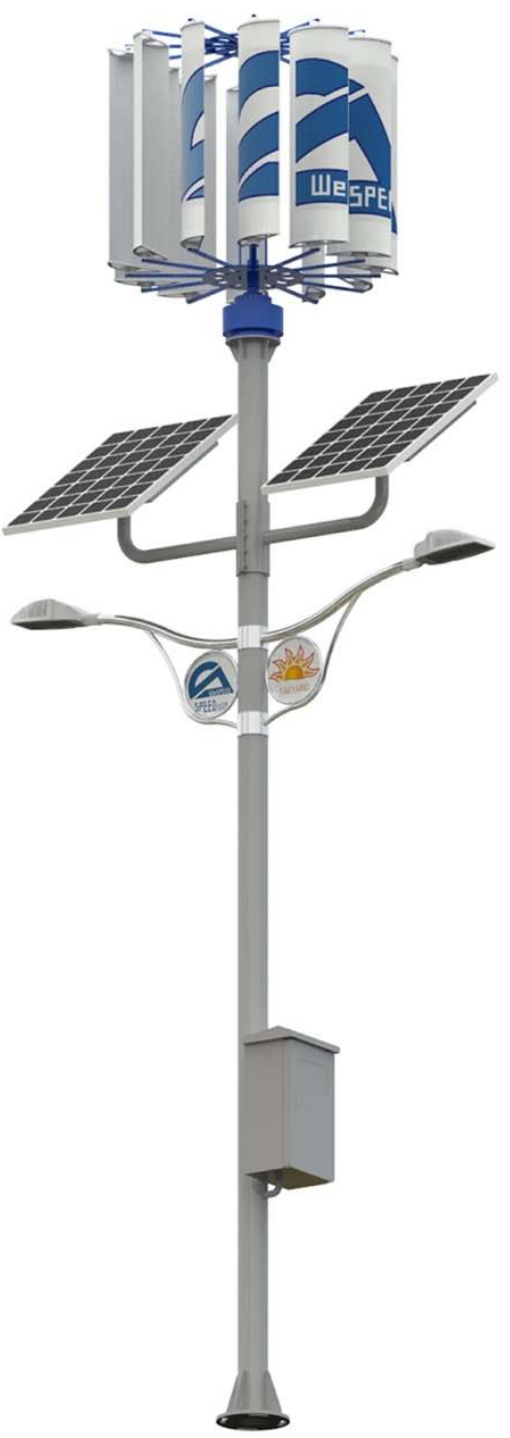

Figure 4. Hybrid.

rotated by wind flow, the rotational energy, which is multiplied by four times through the gearbox connected to the windmill, is transmitted to the generator. The generator produces currents and voltages using a $24 \mathrm{~V}$ controller and the currents are stored in a battery. 


\subsection{Windmill and Gearbox}

The windmill presented in Figure 5 includes an oscillation unit, which optimizes the direction of blades according to drag blades and wind conditions, and an axis of rotation. Also, a gearbox that multiplies the low rotation of the vertical axis windmill as shown in Figure 6. Table 2 shows the specification of the parts employed in the windmill $[1-4,6]$.

\subsection{Generator}

As shown in Figure 7, a coreless generator by AFPM (Axial flux Permanent Magnet), which has been known that it can minimize cogging torque because it does not use an iron core in its coil, is appropriate to small-scaled wind turbine generators that represent difficulties in startup. Table 3 shows the specification of the generator.

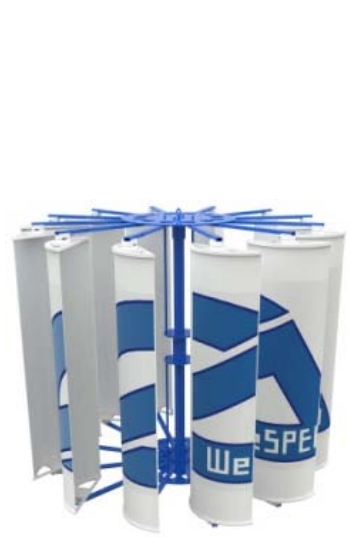

(a) Wind millb

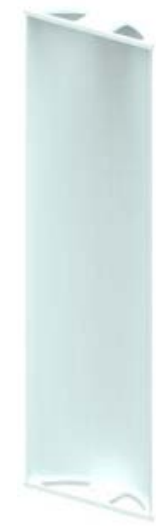

(b) Blade

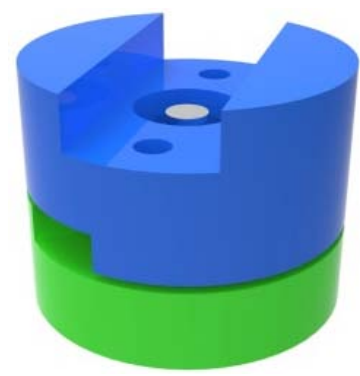

(c) Oscillating unit

Figure 5. Parts of windmill.

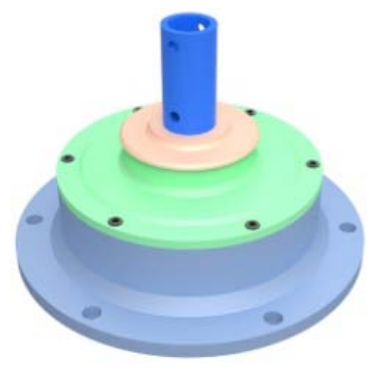

Figure 6. Gearbox.
Table 2. Specification of windmill.

\begin{tabular}{cc}
\hline Diameter of windmill & $\Phi 1460$ \\
\hline Number of Blades & 12 \\
Height of windmill & $1200 \mathrm{~mm}$ \\
Width of blade & $350 \mathrm{~mm}$ \\
Oscillating angle & \pm 35 \\
Gearbox ratio & $1: 4$ \\
\hline
\end{tabular}

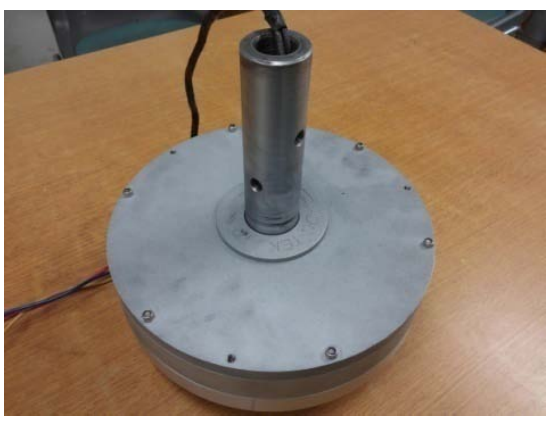

Figure 7. Generator.

Table 3. Parameter of generator.

\begin{tabular}{cc}
\hline AC-Voltage & $24 \mathrm{~V}$ \\
\hline Voltage Output & AC (3Phase) \\
Rotor & Permanent magnet type \\
Startor & Coreless \\
Constant Output & $200 \mathrm{~W}$ \\
Speed Rated & $150 \mathrm{rpm}$ \\
Speed Constant & $191 \mathrm{~V} / \mathrm{rpm}$ \\
Resistance (Line-Line) & $0.728 \Omega$ \\
\hline
\end{tabular}

\subsection{Controller}

As the controller is a hybrid type of wind and solar power and controls $500 \mathrm{~W}$ wind and power respectively. The controller uses a maximum power point tracking (MPPT) method as an off-grid control type. Also, it performs charging/discharging according to batteries. In addition, it includes a system protection function that protects the controller and battery by separating the windmill from the controller as a no-load state through cutting currents in considering voltage increases caused by strong wind flow like a typhoon and prevents the system from over-charging, over-discharging, over-current, and over-voltage. Figure 8 shows the controller and its circuit.

\section{Experiments}

\subsection{Experiment on Mechanical Power}

Figure 9 represents the experimental set-up for measuring the mechanical power. The mechanical power can be measured by pressing the mechanical energy generated by wind speed to a powder brake and torque and RPM sensors are used to measure the power. 


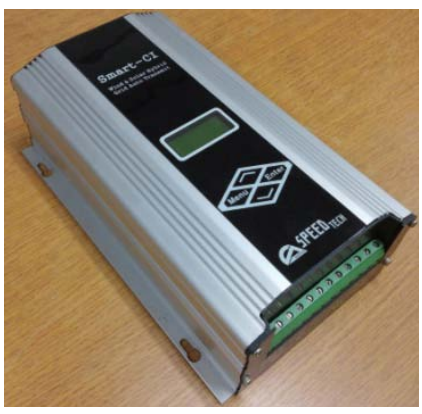

(a) Controller

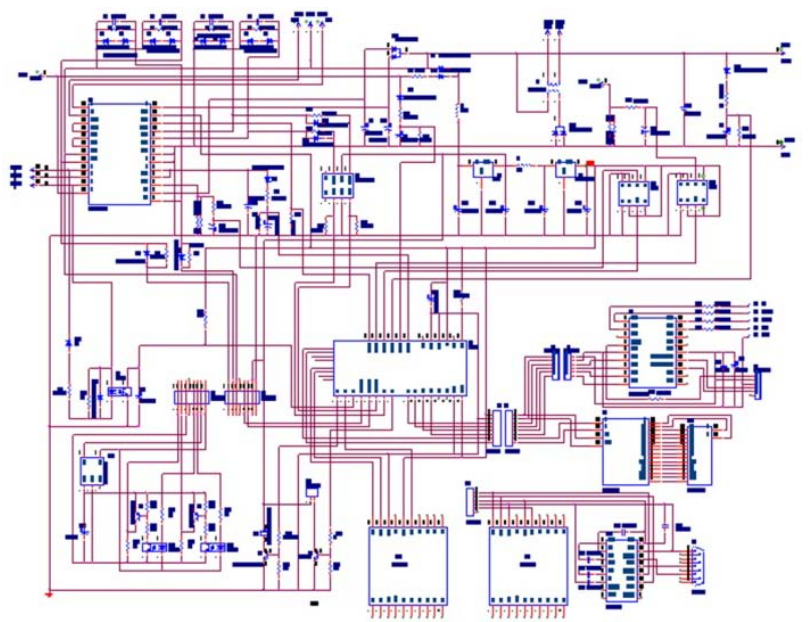

(b) Circuit diagram

Figure 8. Controller.

\subsection{Experiment on Electrical Power}

The experimental set-up for measuring the electrical power is presented in Figure 10. The mechanical energy generated by wind energy is transmitted to the generator and the generator measures voltages and currents using the controller.

\section{Results}

\subsection{Maximum Mechanical Power Line}

Figure 11 shows the torque and RPM graphs presented by measuring the mechanical power. Using these graphs, the mechanical power curve based on the measured torque and RPM can be defined as shown in Figure 12. Also, in measuring the power varying steps, $1-6$, the mechanical power curve can be presented in Figure 13. In addition, the maximum mechanical power line of the windmill can be determined by connecting each maximum point.

\subsection{Generated Electrical Power Line}

Figure 14 shows the electrical power line measured through the experiment of the electrical power. The power produced by the generator according to varies in

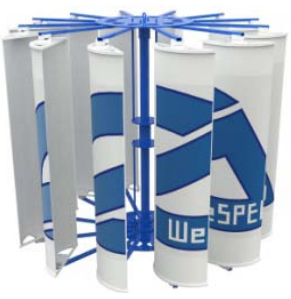

(a) Windmill

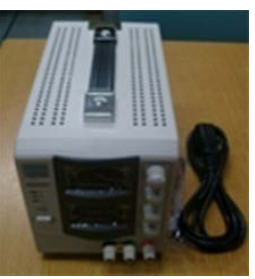

(c) Power supply

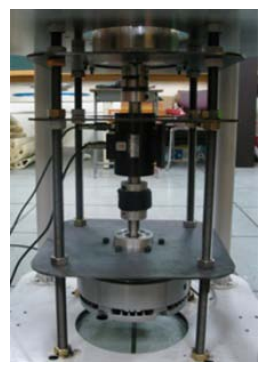

(b) Fixture

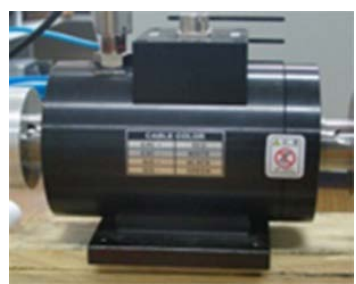

(d) Torque sensor

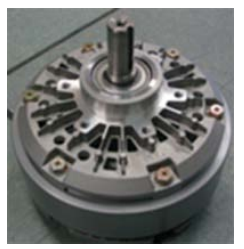

(e) Power brake

Figure 9. Mechanical power measuring system.

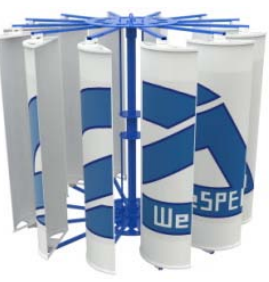

(a) Windmill

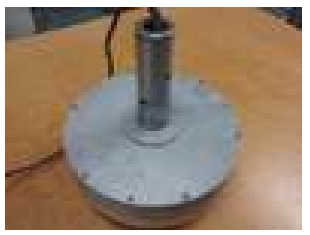

(c) Generator

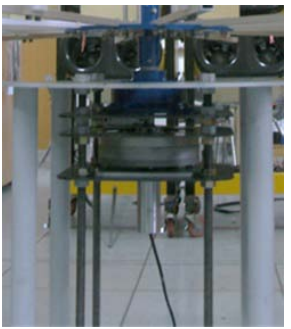

(b) Fixture

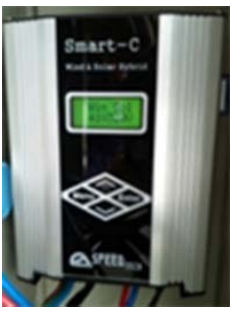

(d) Controller

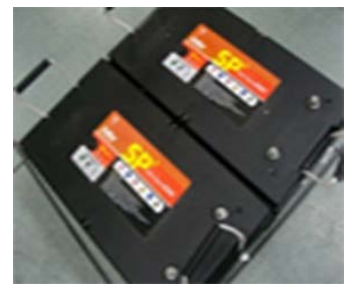

(e) Battery

Figure 10. Electrical power measuring devices. 
시작 시간 : $13 / 07 / 1621: 54: 03$ [화]

종료 시간 : $13 / 07 / 1622: 15: 20$ [화]

\section{X4466.SDR}

Scroll Time : 13/07/16

[화] 22:02:49

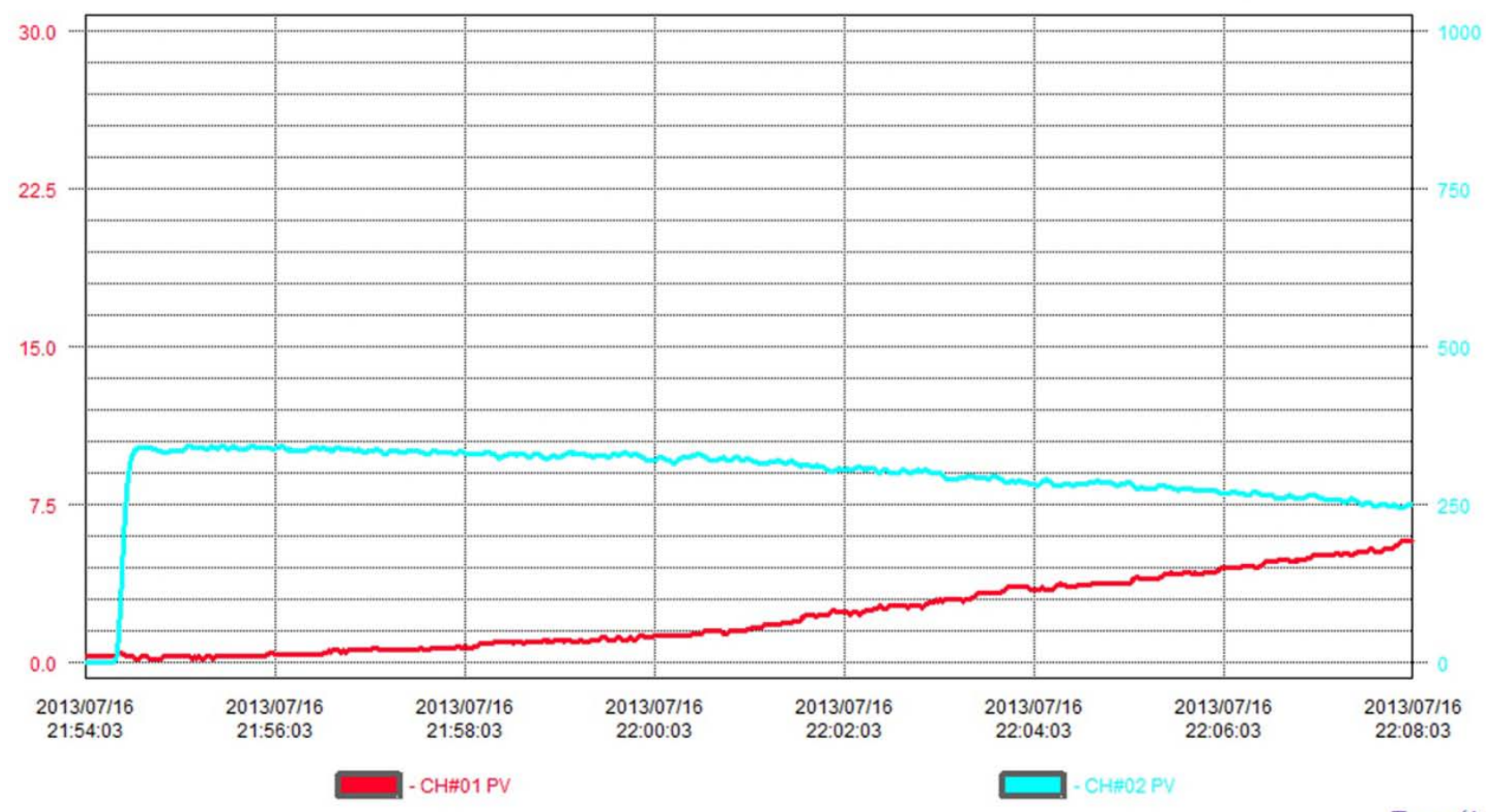

Figure 11. Torque \& RPM.

\section{rpm - Power(W)\&Torque(N • m)}

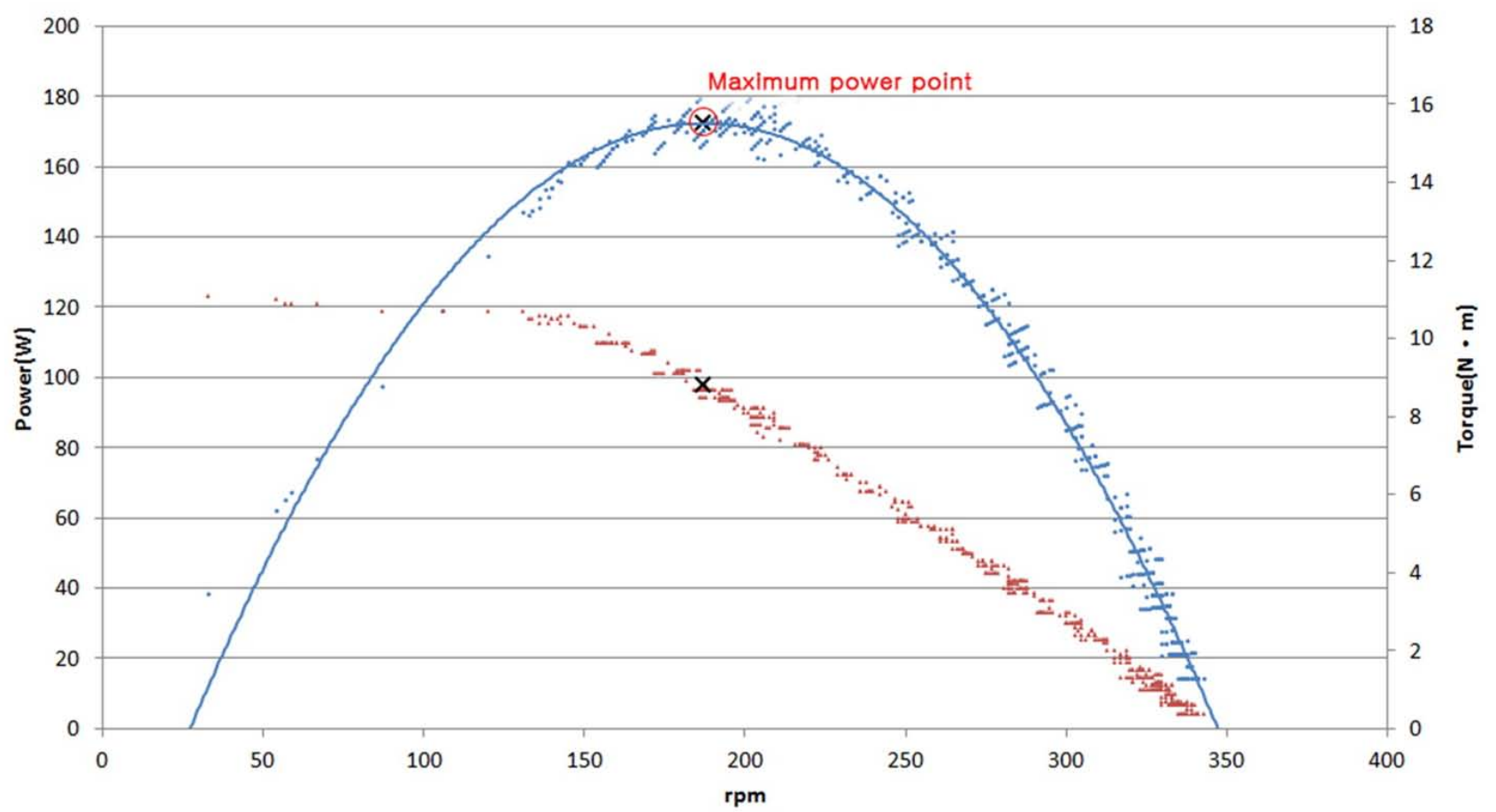

Power $(\mathrm{W}) \quad \times$ Maximum power point $\quad$ Torque $(\mathrm{N} \cdot \mathrm{m}) \quad$ Power reference curve

Figure 12. RPM vs. Power \& Torque curves. 


\section{rpm - Power(W) Reference Curve}

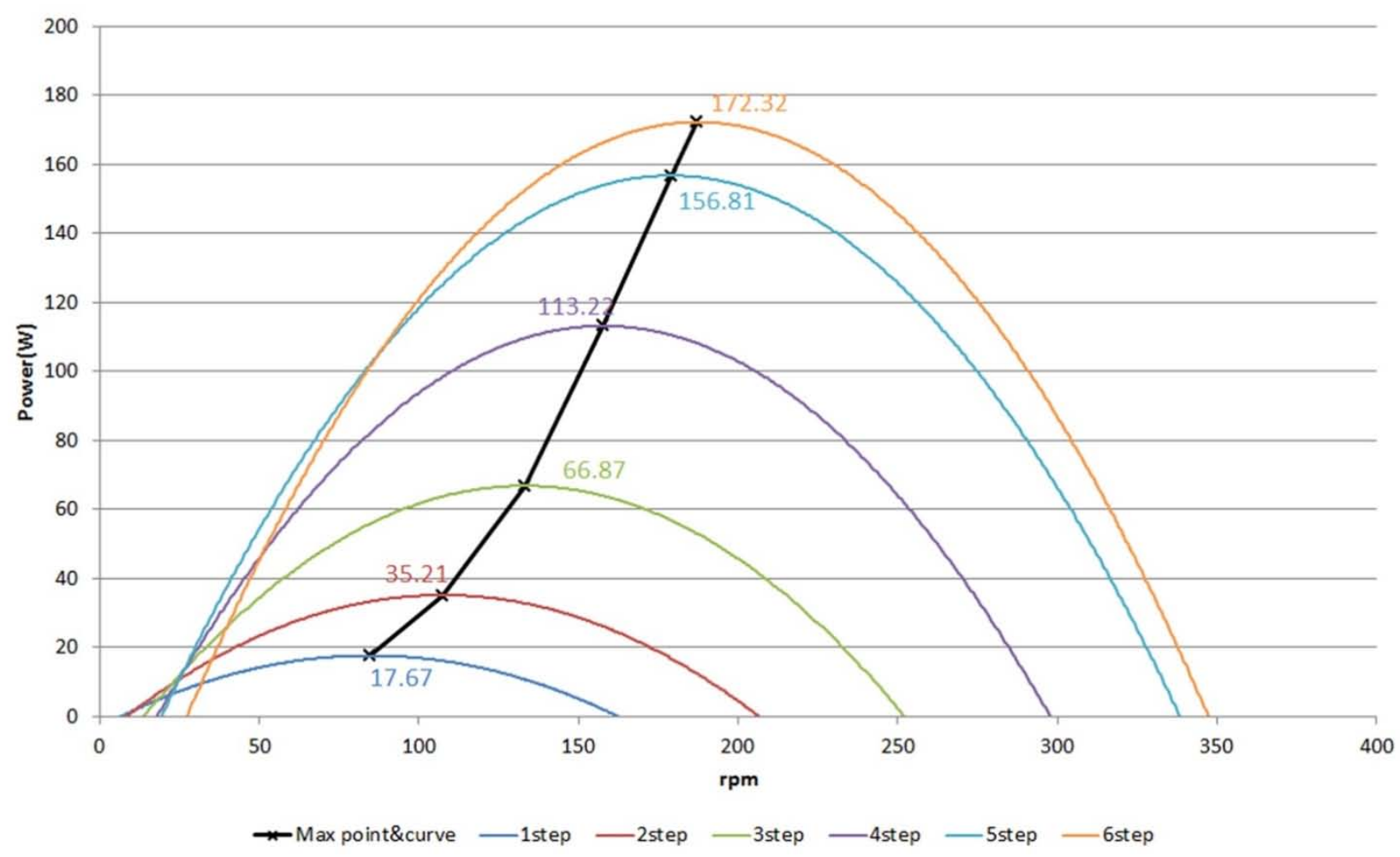

Figure 13. Maximum power line on mechanical power curve.

rpm-Power(W)

[G_SY_150_200_24_C_MH_24_F350_Ф1460_S+35_H1200_x4_P3.5_2FAN_WT6.5_Spline]

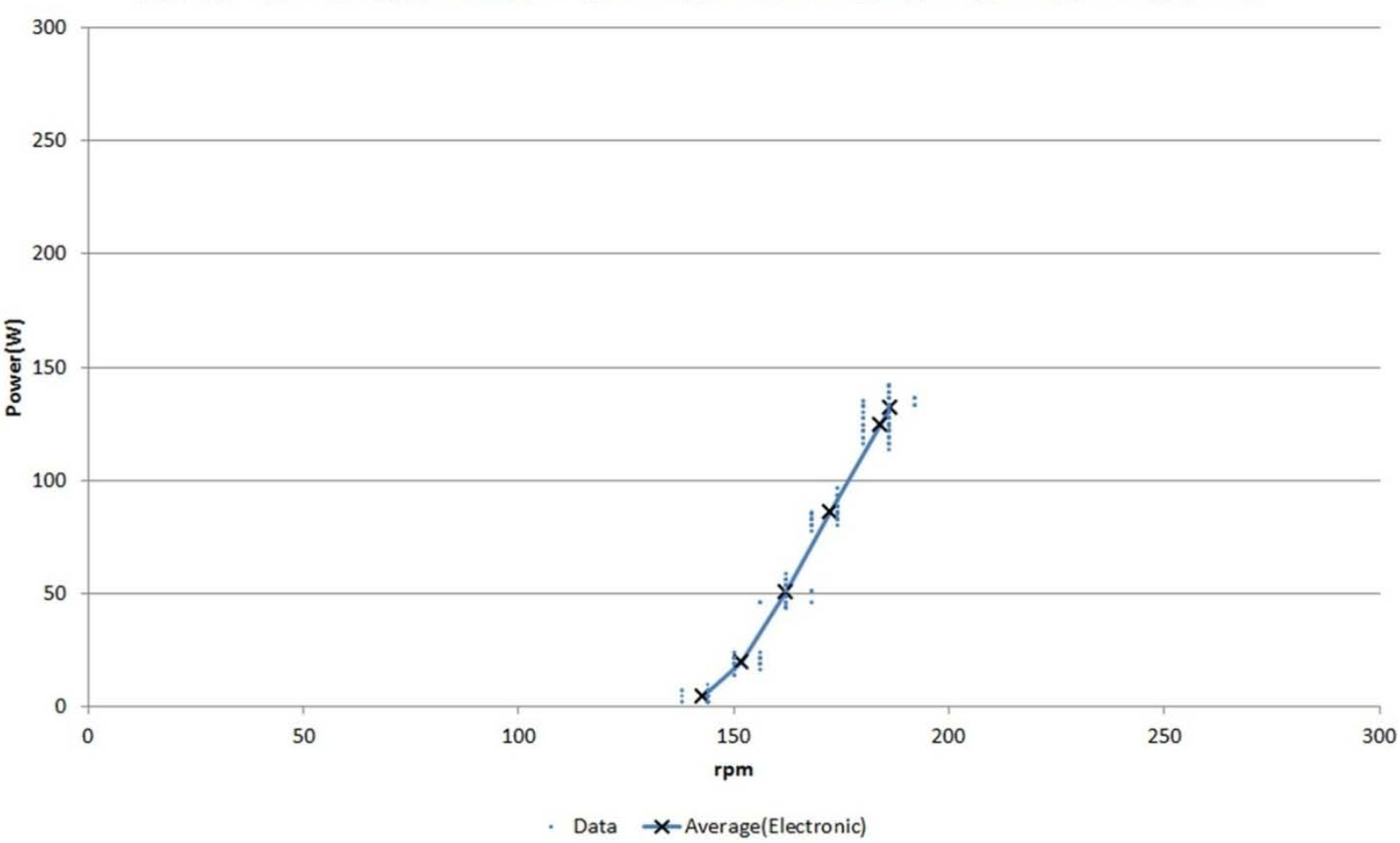

Figure 14. Electrical power curve. 
the wind speed of the blower is stored to a battery and the average of the data obtained by its monitoring is also presented.

\section{Conclusions}

In this study the output of a small-scaled wind turbine generator as a vertical axis drag type is investigated in a simple wind tunnel and the relationship between the electrical and mechanical data is also considered. The smallscaled wind turbine generator is configured with a blade width of $350 \mathrm{~mm}$, a height of $1.2 \mathrm{~m}$, a diameter of $\phi 1460$, an oscillation angle of \pm 35 , and a gear ratio of $1: 4$. Then, the mechanical and electrical power are measured in the simple wind tunnel. Regarding experimental methods, the torque and RPM are measured in the mechanical experiment by applying loads to a powder brake with a constant wind speed for different six blower steps. In the case of the electrical experiment, voltages and currents are measured at the same wind speed as the mechanical experiment. The results are determined by power lines as represented in Figure 15 and the relationship between the mechanical and electrical power in this small wind turbine generator is also verified. A commercial coreless generator, AFPM, is used to measure the power and that is used to determine the maximum power generation point.

Table 4 represents the measured power of the wind turbine generator in which Power 1 of the mechanical power corresponds to the maximum value. The efficiency for the maximum mechanical power is Eff. 1 . In addition, the mechanical power adopted in the condition above $24 \mathrm{~V}$ is presented in Power 2 where the efficiency is presented in Eff. 2. In this experiment, it is verified that the high efficiency more than $75 \%$ is determined at the wind speed more than $5 \mathrm{~m} / \mathrm{s}$ (Step 3). Thus, it is expected that the data analyzed using the empirically obtained mechanical and electrical power will contribute to obtaining the specification of a wind turbine generator, which produces the maximum power.

\section{[G_SY_150_200_24_C_MH_24_F350_Ф1460_S+35_H1200_X4_P3.5_2FAN_WT6.5_Spline]}

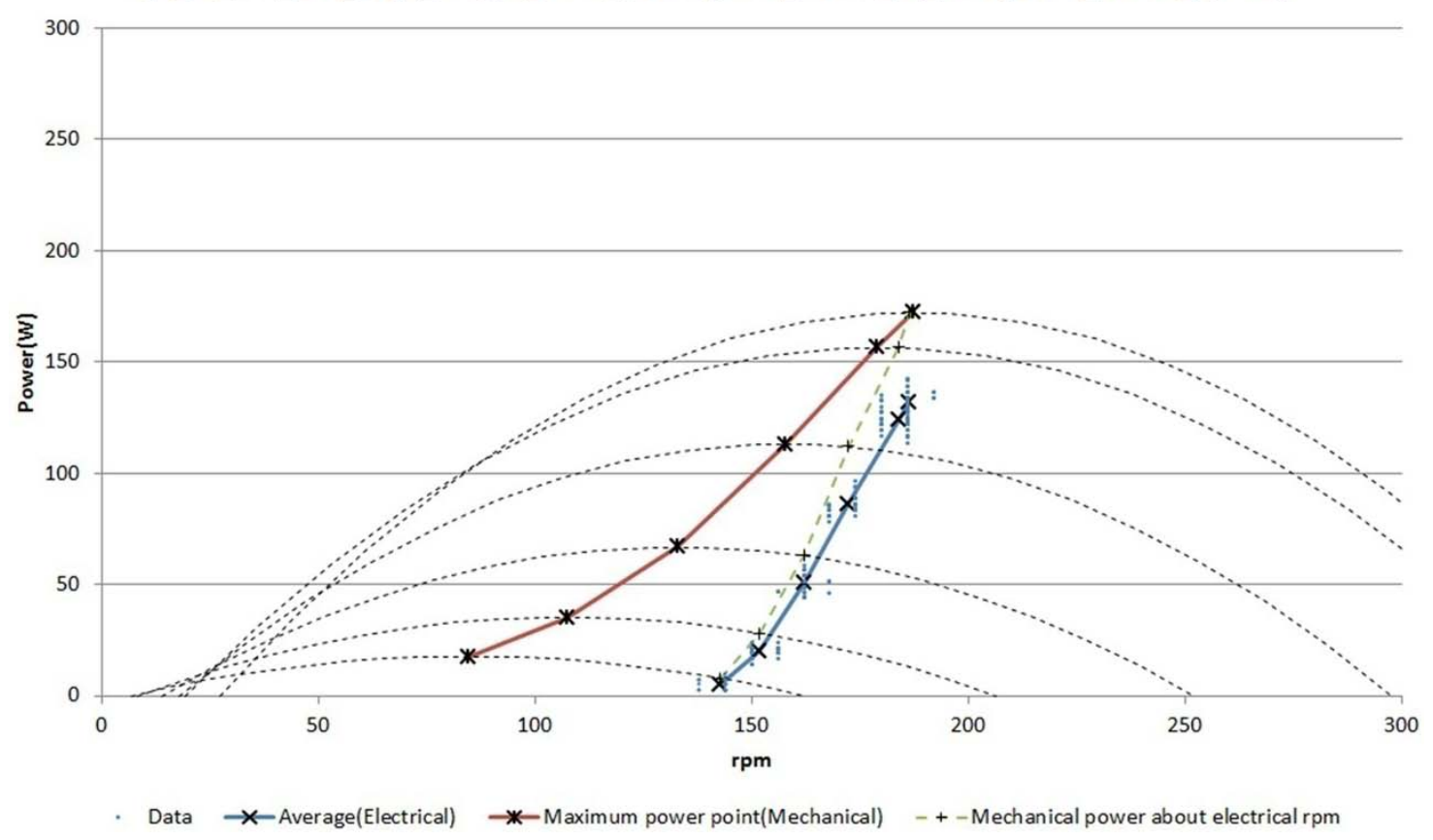

Figure 15. Curves of mechanical and electrical powers.

Table 4. Power data of small-scaled wind generator.

\begin{tabular}{lccccccc}
\hline & \multicolumn{2}{c}{ Electrical } & \multicolumn{3}{c}{ Mechanical } & \multicolumn{2}{c}{ Efficiency (\%) } \\
\cline { 2 - 8 } & Rpm & Power (W) & RPM & Power 1 (W) & Power 2 (W) & Eff.1 & Eff.2 \\
\hline 1 step & 142.8 & 4.68 & 84.51 & 17.67 & 7.77 & 26.47 & 60.21 \\
2 step & 151.8 & 19.76 & 107.4 & 35.21 & 28.14 & 56.14 & 70.23 \\
3 step & 162.15 & 50.6 & 132.96 & 66.87 & 62.86 & 75.67 & 80.49 \\
4 step & 172.35 & 86.02 & 157.79 & 113.22 & 111.99 & 75.98 & 76.81 \\
$\mathbf{5}$ step & 183.9 & 124.26 & 178.85 & 156.81 & 156.65 & 79.24 & 79.32 \\
6 step & 186.45 & 131.82 & 187.25 & 172.32 & 172.31 & 76.5 & 76.5 \\
\hline
\end{tabular}




\section{Acknowledgements}

This research is financially supported by Changwon Natinal University by in 2013-2014.

\section{REFERENCES}

[1] J. H. Kim, H. D. Yang, S. H. Park and J. H. Shin, “Application of New Paradigm for Effectivity of SmallScaled Wind Power Generators," Proceedings of the KSME Spring Annual Meeting, Chang-Won, 10-25 May 2012, pp. 113-118.

[2] H. D. Yang, S. E. An, S. H. Park, J. H. Kim, J. H. Shin and S. M. Kwon, "Dynamic Performance of Vertical Axis Wind Power System,” Transactions of the $\operatorname{KSPE}(B), 2011$, pp. 751-752.
[3] S. H. Park, J. H. Shin, H. E. Yoon and D. W. Kim, “A Study on Kinematic Characteristics of Planetary Gear Train,” Transactions of the KSPE, 1997, p. 643.

[4] S. H. Park, H. D. Yang, J. H. Kim and J. H. Shin, "Design and Application of a Planetary Gearbox for Small Wind Turbines," ICFMD Transactions on Tech Publications, Vol. 271-272, 2013, pp. 818-822. http://dx.doi.org/10.4028/www.scientific.net/AMM.271-2 $\underline{72.818}$

[5] B. S. Hawng, "An Understanding of Advanced Wind Turbines,” 2010, pp.28-30,540-549.

[6] O. R. Kang, M. C. Shin and M. J. Shin, "Windmill of Vertical Axis with Wind Direction Control Blade,” KOR Patent No. 10-1217314. 